
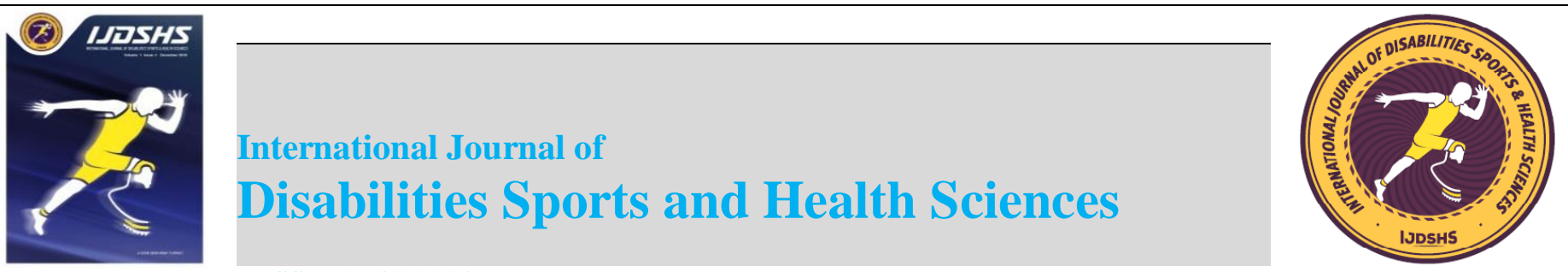

\title{
The Investigation of Acquisition Sufficiency of Physical Education Lesson Aims in A Special Education School in Turkey: A Pilot Study
}

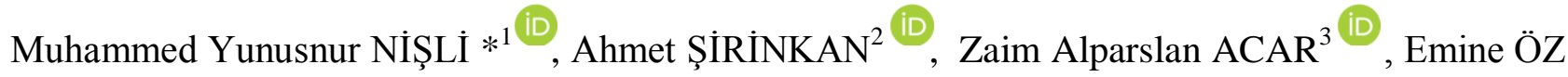 \\ NIŞLI ${ }^{4}$ (iD and Hatice TOY ${ }^{5}$ (iD
}

\author{
${ }^{* 1}$ Faculty of Sports Sciences, Uludag Universty, 16285 Gorukle, Nilufer, Bursa, Turkey \\ ${ }^{2}$ Faculty of Sport Sciences, Department of Recreation, Atatürk University 25240,Yakutiye, Erzurum, Turkey \\ ${ }^{3}$ Faculty of Sports Sciences, Department of Physical Education and Sports, Uludag Universty, 16285 Gorukle, Nilufer, Bursa, \\ Turkey \\ ${ }^{4}$ Şehit Necdet Orhan Regional Boarding Secondary School, 74020 Arıt, Bartın, Turkey \\ ${ }^{5}$ Faculty of Sports Sciences, Uludag Universty, 16285 Gorukle, Nilufer, Bursa, Turkey \\ *Corresponding author: yunusnisli@gmail.com
}

\begin{abstract}
The aim of this study was to examine the acquisition sufficiency of physical education lesson goals with the help of Eurofit Test Battery. The study included 41 students with moderate and severe intellectual disability (ID) (9 female, 32 male and 29 mentally retarded, 6 down syndrome (DS) and 5 autism) who were studying at Recep Birsin Özen Special Education School in Erzurum in Turkey. Physical education lessons were conducted an hour for a day and two days for each week during eight weeks. Before and after 8 weeks of study, Eurofit Tests were applied after measuring the height and the weight of the students. Data were compared in Spss 20 statistics program at $p<0.05$ level. In Eurofit Test parameters of the students with moderate and severe ID; it was found a difference statically in pre-test-post-test comparisons of flamingo balance, plate tapping, sit-up, sit and reach, standing broad jump and 10x5 metre shuttle run. In the physical education and sports classes, the goals chosen according to the students' level improved the physical capacities of the students. The individual goals chosen for the students in the special education school affiliated to the Republic of Turkey Ministry of National Education contributed to the development of balance, fastness, leg strength, upper body movement speed and flexibility of the students and did not only contribute to the development of hand strength, arm strength and abdominal muscle strength of the students. The results of our study and the results of previous studies are parallel.
\end{abstract}

\section{Keywords}

Eurofit Test Battery, Intellectual Disability, Physical Education and Sport, Special Education

\section{INTRODUCTION}

It is known that sport is a tool that supports the muscular and nervous system, mental and physical reactions of humans, physiological and metabolic development of the body. It is emphasized that physical activities have a kind of rehabilitation feature (Beasley, 1982).

Sport is an important activity to get rid of the physical and mental stress of the individuals under the heavy burden of societal life and to physically harmonize with the life conditions (Yüksel, 2018).

One of the most effective assistance for the development of individuals with ID is special education services (Yörükoğlu, 2000). For individuals who are normally developing, special physical education and sport programs in special education services are as necessary as physical 
education and sport in general education (İlhan, Kırımoğlu, Tunçel, \& Altun, 2015).

Purposeful-meaningful and regular-shaped movement programs affect all areas of development of the individuals with ID. The term movement includes sports, dance, exercise, and exploratory movements (Kinali, 2016). The movement motivations of all individuals are in this direction. These experiences gained through movement should not be perceived as a goal alone, but as a fundamental instrument of growth and development.

One of the important educational supports affecting the growth and development of the individuals with ID is physical education programs in which movement skills are gained. There may be various difficulties in implementing these programs. Active participation in such activities may not be possible due to lack of appropriate areas, inadequate materials and lack of expert teachers in the field. In spite of all the difficulties, physical education programs which we believe make a great contribution to all areas of development of individuals should definitely be implemented.

Sport makes individuals fit physically and spiritually (Ersoy, 2004). Sport - especially group sport - is one of the most important supporters of the child's body, mind and social development. In addition to the purpose of maintaining and supporting the healthy situation of sport, it can also serves as a treatment to contribute to the discharge of physical energy and emotion tension (Yalçın \& Akkuş, 2006)

Talents-skills and performance tests and achievement and progress in physical education allow the following-up and grouping of developments within a specific program. As students see their progress in the program, their desire for the program increases. In addition to allowing students and athletes to be classified according to their ability in all activities, special sport branches also allow groups to be matched in school or classroom competitions (Gündüz, 1997). It becomes possible to measure the progress regarding education of students.

It is thought that it may be useful to applicate Eurofit Tests in individuals with different ages to determine healthy living and nutritional conditions, to obtain regular physical activity routine, to provide physical education teachers and coaches with information about the formation- functional characteristics of individuals, to determine universal guidelines about individuals in physical education and sport (Zorba et al., 1995).

In a research by Golubovic et al. (2012) that examined the effects of carefully designed physical exercise programs on the development of physical fitness in children with ID, all the participants were assessed using Eurofit Test Battery. In research by Giagazoglou et al. (2013) physical fitness testing included the use of the following three different physical fitness tests derived from the Eurofit Test Battery, that has been previously applied to individuals with ID and found to be a reliable instrument for adolescents with and without ID. Children with ID can be successful in physical education and sports together with their peers without disabilities when the lucubratory skills are modified. (Sirinkan, 2018). In a research by Sirinkan and Saraçoğlu (2017) for measuring the students' physical parameters improved Eurofit tests for the disabled were used. Eurofit Tests were used in a research by Demirel and Sirinkan (2018) that aimed to search the effect of "Special Activity Education Program" applied in Special Education Rehabilitation Centers.

In a research by Virgil at al. (2015) Plate Tapping test from Eurofit Battery was used to measure repetition speed skill of visually impaired pupils. In another research by Van der Niet et al. (2014) that evaluated the physical activity and physical fitness levels of 8-11 year old children with developmental language disorders and compared this to typically developing age and gender matched controls, physical fitness was measured using five tests of the Eurofit test battery (standing broad jump, sit-ups, handgrip, 10x5 m shuttle run, and the $20 \mathrm{~m}$ shuttle run test). In a research that aims to investigate the physical fitness norms of male and female students in the groups aged 3-6, 25-meter speed, flamingo balance test, plate tapping test, flexibility, standing long jump, grip strength, 30 second shuttle, 30 second push-up, vertical jump, 10x5 meter shuttle run tests from Eurofit test battery were applied (Demirel, Sirinkan, \& Sirinkan, 2016)

In another research on individuals with ID by Salaun and Berthouze-Aranda (2012), Eurofit test battery was applied to Eighty-seven French ID adolescents. In another research on individuals with DS by El et al. (2020), it was aimed to investigate the relationship between physical 
activity levels and the Body Mass index of children with DS and the physical activity was measured with the Eurofit battery. In a research on trainable mentally disabled elementary school students by Kaya et al. (2018), selected Eurofit tests were used to investigate the effect of motion training. In the light of all this information; the aim of this study was to examine the acquisition sufficiency of physical education lesson goals with the help of Eurofit Test Battery.

\section{METHODS}

\section{Participants}

Ethics committee approval was received from the Sub-Ethics Committee of the Faculty of Sport Sciences in Atatürk Universty before the study with the decision number 2016.8.5 / c dated 01.03.2016. The population of the study consisted of students with moderate and severe ID in the 1117 age group studying at Recep Birsin Özen Special Education School in Erzurum Province in Turkey. The sample group of the study consisted of 41 (forty-one) female and male students (11-17 years old) studying at Recep Birsin Özen Special Education Center and attending physical education classes.

\section{Data Collection Process}

Physical fitness of children was evaluated applying the Eurofit Physical Fitness Test Battery (1993). The Eurofit Physical Fitness Test Battery is a set of nine physical fitness tests covering flexibility, speed, endurance and strength. The standardized test battery was devised by the Council of Europe. The test is designed so that it can be performed within 35-40 min, using very simple equipment. Research by Tsigilis, Douda, and Tokmakidis (2002) indicated high reliability of this battery in general population of children, whereas adequate reliability was confirmed when applied to mild ID or individuals without ID (Golubovic, Maksimovic, Golubovic, \& Glumbic, 2012).

Eurofit Test Batteries were applied in the gymnasium of Recep Birsin Özen Special Education School where the students received training. Data were recorded with "Subject Test Follow-up Form". The necessary information about the measurement tool and the procces of the test were given to the students before the tests. The materials used in the tests were introduced. The students were encouraged to be motivated during the test process. Before the students participated in the tests, health checks were made and necessary precautions were taken. Before the tests, the students were not included in any warm-up movement regarding the rules of application of Eurofit Test Batteries.

\section{Test Methods}

The materials used in the tests were prepared in accordance with the instructions shown in Eurofit Test Batteries rules. The ages of the students were noted in accordance with their identities. The Casio stopwatch which has one percent accuracy of a second was used to measure time. Hand grip strength measurements of the students were made with the help of Tekzen (Home Model: EH101 Electronic Hand Dynamometer) brand dynamometer. For other length measurements, 1 meter iron measurement tool was used.

\section{Eurofit test battery includes the following;}

- flamingo balance test which is a single leg balance test;

- plate tapping-tests which measure the speed of limb movement;

- sit-and-reach-flexibility test (using $15 \mathrm{~cm}$ at the level of the feet);

- standing broad jump which measures explosive leg power;

- handgrip test which measures static arm strength;

- sit-ups in 30 seconds which measures trunk strength;

- bent arm hang which measures muscular endurance/ functional strength;

- 10x5-meter shuttle run which measures running speed and agility;

- $20 \mathrm{~m}$ endurance shuttle-run (bleep test) which measures cardiorespiratory endurance (El, Hüzmeli \& Gökçek, 2020)

\section{Anthropometric Measurements}

Height and weight are the measurements used to show and compare the anthropometric properties of individuals with different characteristics. These measurements are also used to determine health status and nutritional adequacy in the development process. The weights of the students were measured with a Sinbo brand precision electronic bathroom weighing scale with a sensitivity of $0.1 \mathrm{~kg}$. For weight measurements, the students were allowed to go to the scale with as few clothes as possible. Standard wall scale was used for height measurements of the students. 
While taking the height measurements, the student was allowed to stand upright without shoes, two legs sticking together, knees stretched, back of the head, shoulders and heel leaning against the wall. Students stood at a 90-degree angle to the wall.
The measurement was made with a small ruler from the point where the students rest their head to the wall. The data were recorded. Measurements were determined with a precision of $0.1 \mathrm{~cm}$.

Table 1. Eurofit test battery applied for students with id, ds and autism.

\begin{tabular}{|c|c|c|c|c|}
\hline Dimension & Factor & Description & Eurofit Test & $\begin{array}{l}\text { Second } \\
\text { Choice }\end{array}$ \\
\hline 1. Strength & $\begin{array}{l}\text { a. Static Strength } \\
\text { b.Explosive Strength }\end{array}$ & $\begin{array}{l}\text {-Maximum Strength } \\
\text {-Maximal Muscular Power }\end{array}$ & $\begin{array}{l}\text {-Arm pull } \\
\text {-Standing broad jump }\end{array}$ & $\begin{array}{l}\text {-Hand grip } \\
\text {-Vertical } \\
\text { jump }\end{array}$ \\
\hline $\begin{array}{l}\text { 2. Muscular } \\
\text { Endurance }\end{array}$ & $\begin{array}{l}\text { a. Functional Strength } \\
\text { (dynamic strength) } \\
\text { b. Abdominal Strength } \\
\text { (dynamic trunk strength) }\end{array}$ & $\begin{array}{ll}\text { 1-Upper limb } & \text { muscular } \\
\text { endurance } & \\
\text { n-Abdominal } & \text { muscular- } \\
\text { endurance } & \\
\end{array}$ & $\begin{array}{l}\text { r } \\
\text {-Bent arm hang } \\
\text { r-Sit-ups in } 30 \text { seconds }\end{array}$ & \\
\hline 4. Flexıbılıty & $\begin{array}{lll}\text { Flexibility } & \text { (extent } \\
\text { flexibility) }\end{array}$ & $\begin{array}{l}\text { fArticulo-muscular range of } \\
\text { movement }\end{array}$ & Sit and reach & \\
\hline 5. Speed & $\begin{array}{l}\text { a. Speed of limb } \\
\text { movement } \\
\text { b. Running Speed }\end{array}$ & $\begin{array}{l}\text { o-Segmental repetitive- } \\
\text { velocity } \\
\text {-Total body velocity }\end{array}$ & $\begin{array}{l}\text { e-Plate tapping time for } 25 \\
\text { cycles } \\
\text {-Shuttle run } 10 \times 5 \text { metres }\end{array}$ & $50 \mathrm{~m}$ sprint \\
\hline 6. Balance & Total body balance & $\begin{array}{l}\text { Coordination of total body } \\
\text { equilibrium }\end{array}$ & $\begin{array}{l}\text { Standing on one foot on a } \\
\text { 'beam for } 1 \text { minute, } \\
\text { 'flamingo' balance }\end{array}$ & \\
\hline
\end{tabular}

\section{Statistical analysis}

In our study, SPSS 20 package program was used for the analysis of data obtained. Normality of the distribution of values was checked by the Shapiro-wilk test. Obtained data from the students with ID, DS and Autism compared according to Shapiro-wilk, MannWhitney U, Wilcoxon Signed Ranks, The KruskalWallis $\mathrm{H}$ tests. The Wilcoxon Signed Ranks Test was used to determine whether there was a significant difference between pre-test post-test results for the variables of balance, fastness, standing long jump, hand grip, sit-ups, bent arm hang, shuttle run and flexibility dependent variables. The Wilcoxon Signed Ranks Test is used to check whether the difference between two paired distributions in a group is significant (Baştürk, 2011).

The Mann-Whitney U Test was used to determine whether there was a significant difference between the posttest values of the students for the independent variables of height, weight, gender and disability level consisting of two groups. Mann-Whitney U Test is used to check whether the data collected from two unrelated groups differ significantly from each other (Büyüköztürk, 2010). The Kruskal-Wallis H Test was used to show whether there was a significant difference between the post-test values of the subject group for the disability type variable consisting of three groups. In the analysis, high rank means for balance, standing long jump, hand grip, sit-ups, bent arm hang and flexibility dependent variables and low rank means for fastness and shuttle run dependent variables were considered to be positive. For the analysis of the data, it was seen as 0.05 significance level.

\section{RESULTS}

Firstly, it was examined whether the data met the normal distribution assumptions. In this context, Shapiro-Wilk Test was performed for each dependent variable and the calculated values are given in Table 2. According to Table 2, it was concluded that the data were not normally distributed for all dependent variables $(\mathrm{p}<0.05)$. Nonparametric tests were used to analyze the data. 
Table 2. Shapiro-wilk test results of normality of distribution.

\begin{tabular}{lccc}
\hline Dependent variables & Statistics & df & p \\
\hline Balance & .926 & 41 & .011 \\
Fastness & .927 & 41 & .012 \\
Standing long jump & .865 & 41 & .001 \\
Hand grip & .945 & 41 & .048 \\
Sit-ups & .864 & 41 & .001 \\
Bent arm hang & .939 & 41 & .030 \\
Shuttle run & .854 & 41 & .000 \\
Flexibility & .899 & 41 & .002 \\
\hline
\end{tabular}

df: Degree of freedom, p: Significance Level determined as $\mathrm{p}<0.05$.

\section{Research Group}

Demographic information about the students participating in the research was given in Table 3 .

Table 3. Demographic data of the research group

\begin{tabular}{lcc}
\hline Variables & f & \% \\
\hline Height & 21 & 51.2 \\
$140-160 \mathrm{~cm}$. & 20 & 48.8 \\
$161-181 \mathrm{~cm}$. & 41 & 100 \\
Total & & \\
Weight & 20 & 48.8 \\
$39-55 \mathrm{~kg}$. & 21 & 51.2 \\
More than 55 kg. & 41 & 100 \\
Total & & \\
Gender & 32 & 78 \\
Male & 9 & 22 \\
Female & 41 & 100 \\
Total & & \\
Disability type & 29 & 70.7 \\
Intellectual disability & 6 & 14.6 \\
Down syndrome & 6 & 14.6 \\
Autism & 41 & 100 \\
Total & & \\
Disability level & 27 & 65.9 \\
Moderate & 14 & 34.1 \\
Severe & 41 & 100 \\
Total & & \\
\hline
\end{tabular}

The heights of $51.2 \%$ of the students participating in the research were between 140-160 $\mathrm{cm}$ and $48.8 \%$ were between $161-181 \mathrm{~cm}$. The weights of $48.8 \%$ of the students were between 39 $55 \mathrm{~kg}$ and $51.2 \%$ were more than $55 \mathrm{~kg}$. $78 \%$ of the students were males and $22 \%$ were females. $70.7 \%$ of the students with ID, $14.6 \%$ with DS and $14.6 \%$ had autism. The level of disability of $65.9 \%$ of students were moderate while $34.1 \%$ were heavy.

\section{The results for all students}

According to flamingo balance, tapping disc, standing long jump, hand grip, bent arm hang, 10x5 shuttle run and sit-and-reach test results for all students, Wilcoxon Signed Ranks Test was used to determine whether there was a significant difference between the pre-test post-test values of levels of the students. The results were indicated in Table 4. 
Table 4. Values of flamingo balance, tapping disc, standing long jump, hand gripping, bent arm hang, $10 \times 5$ shuttle run and sit-and-reach tests for all students.

\begin{tabular}{|c|c|c|c|c|c|c|c|c|}
\hline & $\begin{array}{c}\text { Flamingo } \\
\text { Balance } \\
\text { Test }\end{array}$ & $\begin{array}{l}\text { Tapping } \\
\text { Discs }\end{array}$ & $\begin{array}{c}\text { Standing } \\
\text { Long Jump }\end{array}$ & $\begin{array}{c}\text { Hand } \\
\text { Gripping }\end{array}$ & Sit-Up & $\begin{array}{l}\text { Bent Arm } \\
\text { Hang }\end{array}$ & $\begin{array}{c}\text { 10x5 } \\
\text { Shuttle } \\
\text { Run }\end{array}$ & $\begin{array}{c}\text { Sit-and- } \\
\text { Reach }\end{array}$ \\
\hline $\begin{array}{l}\text { Pretest-Posttest } \\
\text { values(n=41) }\end{array}$ & $\begin{array}{l}Z=-5.374 \\
p=.000\end{array}$ & $\begin{array}{l}Z=-5.405 \\
p=.000\end{array}$ & $\begin{array}{l}Z=-5.589 \\
p=.000\end{array}$ & $\begin{array}{l}Z=-0.695 \\
p=.487\end{array}$ & $\begin{array}{l}\mathrm{Z}= \\
0.210 \\
\mathrm{p}=.834\end{array}$ & $\begin{array}{l}-\mathrm{Z}= \\
1.257 \\
\mathrm{p}=.209\end{array}$ & $\begin{array}{l}\mathrm{Z}= \\
5.635 \\
\mathrm{p}=.000\end{array}$ & $\begin{array}{l}\mathrm{Z}= \\
-5.516 \\
p=.000\end{array}$ \\
\hline
\end{tabular}

$\mathrm{n}$ : Number of subjects, Z: Difference score, $\mathrm{p}$ : Statistical significance was determined as $\mathrm{p}<0.05$.

When the data in Table 4. were analyzed respectively, a significant difference was found between the pre-test post-test values of the balance levels of students according to flamingo balance test $(Z=-5.374 ; p<0.05)$. A significant difference was found between the pre-test and post-test values of fastness levels of the students according to disc tapping movement $(\mathrm{Z}=-5.405 ; \mathrm{p}<0.05)$. A significant difference was found between the pretest and post-test measurements regarding long jump levels of the students $(Z=-5.589 ; \mathrm{p}<0.05)$. There was no significant difference between pretest and post-test measurements regarding hand grip strength levels of the students $(Z=-0.695$; $p$ > $0.05)$. There was no significant difference between the pre-test and post-test measurements regarding sit-ups movement levels of the students $(\mathrm{Z}=$ $0.210 ; \mathrm{p}>0.05)$. There was no significant difference between the pre-test and post-test values regarding bent arm hang levels of the students $(\mathrm{Z}=$ $-1.257 ; \mathrm{p}>0.05)$. A significant difference was found between the pre-test and post-test values regarding shuttle run levels of the students $(\mathrm{Z}=$ 5.635; $\mathrm{p}<0.05)$. A significant difference was found between the pre-test and post-test values regarding flexibility levels of the students according to sitand-reach movement $(\mathrm{Z}=-5.516 ; \mathrm{p}<0.05)$.

\section{The results according to the height variable}

According to the height variable The MannWhitney U Test was used to determine wheter there was the significant difference between posttest results of flamingo balance, tapping disc, standing long jump, hand grip, bent arm hang, $10 \times 5$ shuttle run and sit-and-reach levels of the students and the results were indicated in Table 5.

Table 5. Values of flamingo balance, tapping disc, standing long jump, hand grip, bent arm hang, 10x5 shuttle run and sit-and-reach test levels according to the length variable of the students.

\begin{tabular}{|c|c|c|c|c|c|c|c|c|}
\hline & $\begin{array}{c}\text { Flamingo } \\
\text { Balance } \\
\text { Test }\end{array}$ & $\begin{array}{l}\text { Tapping } \\
\text { Disc }\end{array}$ & $\begin{array}{c}\text { Standing } \\
\text { Long Jump }\end{array}$ & $\begin{array}{c}\text { Hand } \\
\text { Gripping }\end{array}$ & Sit-Up & $\begin{array}{c}\text { Bent Arm } \\
\text { Hang }\end{array}$ & $\begin{array}{c}10 \times 5 \\
\text { Shuttle } \\
\text { Run }\end{array}$ & $\begin{array}{c}\text { Sit-and- } \\
\text { Reach }\end{array}$ \\
\hline \multicolumn{9}{|l|}{$\begin{array}{c}\text { Between 140-160 } \\
\text { CM }(n=21)\end{array}$} \\
\hline $\begin{array}{l}\text { Between 161-181 } \\
\text { CM }(n=20)\end{array}$ & $\begin{array}{c}\mathrm{Z}=-1.372 \\
\mathrm{p}=.170\end{array}$ & $\begin{array}{c}Z=-1.963 \\
p=.050\end{array}$ & $\begin{array}{c}\mathrm{Z}=-3.810 \\
\mathrm{p}=.000\end{array}$ & $\begin{array}{c}\mathrm{Z}=-3.810 \\
\mathrm{p}=.000\end{array}$ & $\begin{array}{c}\mathrm{Z}=-1.504 \\
\mathrm{p}=.133\end{array}$ & $\begin{array}{c}\mathrm{Z}=-3.979 \\
\mathrm{p}=.000\end{array}$ & $\begin{array}{c}\mathrm{Z}=-1.722 \\
\mathrm{p}=.085\end{array}$ & $\begin{array}{c}\mathrm{Z}=-0.655 \\
\mathrm{p}=.513\end{array}$ \\
\hline
\end{tabular}

n: Number of subjects, Z: Difference score, $\mathrm{p}$ : Statistical significance was determined as $\mathrm{p}<0.05$.

When the data in Table 5. were examined respectively, no significant difference was found between posttest results of balance levels of students according to height variable $(Z=-1.372$; p> 0.05). No significant difference was found between the post-test values of fastness levels of students $(Z=-1.963 ; p>0.05)$. A significant difference was found between the post-test values of the standing long jump levels of students $(\mathrm{Z}=$ $3.810 ; \mathrm{p}<0.05)$. A significant difference was found between the post-test results of the hand strength levels of the students $(Z=-3.810 ; p<0.05)$. No significant difference was found between the posttest values of sit-ups movement levels of the students $(Z=-1.504 ; p>0.05)$. 
A significant difference was found between the post-test values of bent arm hang levels of the students $(Z=-3.979 ; \mathrm{p}<0.05)$. No significant difference was found between the post-test values The results according to the weight variable

According to the weight variable, The MannWhitney U Test was used to determine whether there was a significant difference between the post-test values of flamingo balance, tapping disc, of shuttle run levels of students $(Z=-1.722 ; p>$ $0.05)$. No significant difference was found between the post-test values of flexibility levels of students $(\mathrm{Z}=-0.655 ; \mathrm{p}>0.05)$.

standing long jump, hand grip, bent arm hang, $10 \times 5$ shuttle run and sit-and-reach levels of the students. The findings were as indicated in Table 6.

Table 6.Values of flamingo balance, tapping disc, standing long jump, hand grip, bent arm hang, 10x5 shuttle run and sit-and-reach test levels according to the weight variable of the students.

\begin{tabular}{|c|c|c|c|c|c|c|c|c|}
\hline & $\begin{array}{c}\text { Flamingo } \\
\text { Balance } \\
\text { Test }\end{array}$ & $\begin{array}{l}\text { Tapping } \\
\text { Disc }\end{array}$ & $\begin{array}{l}\text { Standing } \\
\text { Long Jump }\end{array}$ & $\begin{array}{c}\text { Hand } \\
\text { Gripping }\end{array}$ & Sit-Up & $\begin{array}{c}\text { Bent Arm } \\
\text { Hang }\end{array}$ & $\begin{array}{c}10 \times 5 \\
\text { Shuttle } \\
\text { Run }\end{array}$ & $\begin{array}{l}\text { Sit-and- } \\
\text { Reach }\end{array}$ \\
\hline $\begin{array}{l}39-55 \text { kg. }(n=20) \\
55+\text { kg. }(n=21)\end{array}$ & $\begin{array}{c}\mathrm{Z}=-1.176 \\
\mathrm{p}=.240\end{array}$ & $\begin{array}{c}Z=-1.191 \\
p=.234\end{array}$ & $\begin{array}{c}\mathrm{Z}=-0.431 \\
\mathrm{p}=.667\end{array}$ & $\begin{array}{c}\mathrm{Z}=-2.226 \\
\mathrm{p}=.026\end{array}$ & $\begin{array}{c}\mathrm{Z}=-0.706 \\
\mathrm{p}=.480\end{array}$ & $\begin{array}{c}Z=-1.171 \\
p=.242\end{array}$ & $\begin{array}{c}\mathrm{Z}=-1.380 \\
\mathrm{p}=.168\end{array}$ & $\begin{array}{c}\mathrm{Z}=-0.423 \\
\mathrm{p}=.672\end{array}$ \\
\hline
\end{tabular}

n: Number of subjects, Z: Difference score, $\mathrm{p}$ : Statistical significance was determined as $\mathrm{p}<0.05$.

When the data in Table 6. were examined respectively, no significant difference was found between the post-test values of balance levels of the students according to the weight variable $(\mathrm{Z}=$ $1.176 ; \mathrm{p}>0.05)$. No significant difference was found between the post-test values of fastness levels of the students $(Z=-1.191 ; p>0.05)$. No significant difference was found between the posttest values of standing long jump levels of the students $(Z=-0.431 ; p>0.05)$. A Significant difference was found between the post-test values of hand strength levels of students $(Z=-2.226$; $p$ $<0.05)$. No significant difference was found between the post-test values of sit-ups levels of the students $(Z=-0.706 ; p>0.05)$. No significant difference was found between the post-test values of shuttle run levels of the students $(Z=-1.380 ; p>$ $0.05)$. No significant difference was found between the post-test values of flexibility levels of the students $(Z=-0.423 ; p>0.05)$.

\section{The results according to the gender variable}

According to the gender variable, The Mann-Whitney U Test was used to determine whether there was a significant difference between the post-test values of flamingo balance, tapping disc, standing long jump, hand grip, bent arm hang, 10x5 shuttle run and sit-and-reach levels of the students. The findings were as indicated in Table 7.

Table 7. Values of flamingo balance, tapping disc, standing long jump, hand grip, bent arm hang, 10x5 shuttle run and sit-and-reach test levels according to the gender variable of the students.

\begin{tabular}{|c|c|c|c|c|c|c|c|c|}
\hline & $\begin{array}{c}\text { Flamingo } \\
\text { Balance } \\
\text { Test }\end{array}$ & $\begin{array}{l}\text { Tapping } \\
\text { Disc }\end{array}$ & $\begin{array}{c}\text { Standing } \\
\text { Long Jump }\end{array}$ & $\begin{array}{c}\text { Hand } \\
\text { Gripping }\end{array}$ & Sit-Up & $\begin{array}{c}\text { Bent Arm } \\
\text { Hang }\end{array}$ & $\begin{array}{c}10 x 5 \\
\text { Shuttle } \\
\text { Run }\end{array}$ & $\begin{array}{l}\text { Sit-and- } \\
\text { Reach }\end{array}$ \\
\hline $\begin{array}{l}\text { Female }(n=9) \\
\text { Male }(n=32)\end{array}$ & $\begin{array}{c}\mathrm{Z}=-0.426 \\
\mathrm{p}=.670\end{array}$ & $\begin{array}{c}\mathrm{Z}=-0.332 \\
\mathrm{p}=.740\end{array}$ & $\begin{array}{c}\mathrm{Z}=-3.041 \\
\mathrm{p}=.002\end{array}$ & $\begin{array}{c}Z=-3.542 \\
p=.000\end{array}$ & $\begin{array}{c}Z=-0.995 \\
p=.320\end{array}$ & $\begin{array}{c}Z=-2.748 \\
p=.006\end{array}$ & $\begin{array}{c}\mathrm{Z}=-0.317 \\
\mathrm{p}=.751\end{array}$ & $\begin{array}{c}Z=-0.692 \\
p=.525\end{array}$ \\
\hline
\end{tabular}

n: Number of subjects, Z: Difference score, $\mathrm{p}$ : Statistical significance was determined as $\mathrm{p}<0.05$.

When the data in Table 7. were examined respectively, no significant difference was found between the post-test values of balance levels the students $(Z=-0.426 ; \mathrm{p}>0.05)$. No significant difference was found between the post-test values of fastness levels of the students $(Z=-0.332 ; p>$ $0.05)$. 
A significant difference was found between the posttest values of standing long jump levels of the students $(Z=-3.041 ; p<0.05)$. A significant difference was found between the post-test values of hand grip of the students $(\mathrm{Z}=-3.542 ; \mathrm{p}<0.05)$. No significant difference was found the post-test values of sit-ups levels of the students $(Z=-0.995$; $p>0.05)$. A significant difference was found the post-test values of bent arm hang levels of the students $(Z=-2.748 ; p<0.05)$. No significant difference was found between the post-test values of shuttle run levels of the students $(Z=-0.317$; $>$
0.05). No significant difference was found the post-test values of flexibility levels of students $(\mathrm{Z}$ $=-0.692 ; \mathrm{p}>0.05)$.

\section{The results according to the disability type}

According to the disability type variable, Kruskal-Wallis $\mathrm{H}$ Test was used to determine whether there was a significant difference between the post-test values of flamingo balance, tapping disc, standing long jump, hand grip, bent arm hang, 10x5 shuttle run and sit-and-reach levels of the students. The findings were as indicated in Table 8 .

Table 8. Values of flamingo balance, tapping disc, standing long jump, hand grip, bent arm hang, 10x5 shuttle run and sit-and-reach test levels according to the disability type variable of the students.

\begin{tabular}{ccccccccc}
\hline & $\begin{array}{c}\text { Flamingo } \\
\text { Balance } \\
\text { Test }\end{array}$ & $\begin{array}{c}\text { Tapping } \\
\text { Disc }\end{array}$ & $\begin{array}{c}\text { Standing } \\
\text { Long Jump }\end{array}$ & $\begin{array}{c}\text { Hand } \\
\text { Gripping }\end{array}$ & Sit-Up & $\begin{array}{c}\text { Bent Arm } \\
\text { Hang }\end{array}$ & $\begin{array}{c}\text { 10x5 } \\
\text { Shuttle } \\
\text { Run }\end{array}$ & $\begin{array}{c}\text { Sit-and- } \\
\text { Reach }\end{array}$ \\
\hline $\begin{array}{c}\text { Intellectual } \\
\text { disability (n=29) }\end{array}$ & $\mathrm{X} 2=3.615$ & $\mathrm{X} 2=3.233$ & $\mathrm{X} 2=1.233$ & $\mathrm{X} 2=8.062$ & $\mathrm{X} 2=7.913 \mathrm{X} 2=1.475$ & $\mathrm{X} 2=$ & $\mathrm{X} 2=\mathrm{11.533}$ & 11.533 \\
$\begin{array}{c}\text { Down } \\
\text { Syndrome(n=6) }\end{array}$ & $\mathrm{p}=.164$ & $\mathrm{p}=.199$ & $\mathrm{p}=.483$ & $\mathrm{p}=.018$ & $\mathrm{p}=.019$ & $\mathrm{p}=.478$ & $\mathrm{p}=.003$ & $\mathrm{p}=.003$ \\
Autism (n=6) & & & & & & & & \\
\hline
\end{tabular}

$\mathrm{n}$ : Number of subjects, df: degree of freedom, $\mathrm{p}$ : Statistical significance was determined as $\mathrm{p}<0.05$.

When the data in Table 8. were examined respectively, no significant difference was found between the post-test values of balance levels of the students according to the disability type variable (Chi-Square $=3.615 ; \mathrm{p}>0.05)$ No significant difference was found between the posttest values of levels of fastness of the students (Chi-Square $=3.233 ; \mathrm{p}>0.05)$. No significant difference was found between the post-test values of standing long jump levels of the students (ChiSquare $=1.233 ; \mathrm{p}>0.05)$. A significant difference was found between the post-test values of hand gripping levels of the students (Chi-Square = 8.062; $\mathrm{p}$ <0.05). "Mann-Whitney U Test" was used in order to determine which groups had significant difference. Thus, a significant difference was found between the students with and autism and the students with DS in favor of the the students with ID and autism. It was found that the hand grip level values of the students with ID and autism were higher than the students with DS.

A significant difference was found between the post-test values of sit-ups levels of the students (Chi-Square $=7.913 ; \mathrm{p}<0.05)$. "Mann-Whitney U
Test" was used in order to determine which groups had significant difference. Thus, a significant difference was found between the students with ID and DS and the students with autism in favor of the students with ID and DS. It was found that the values of sit-ups levels of the students with ID and DS were higher than the students with autism. No significant difference was found between the posttest values of bent arm hang levels of the students (Chi-Square $=1.475 ; \mathrm{p}>0.05)$ According to this, although the disability type was not an effective factor in terms of bent arm hang levels of the students, it could be said that although there was no statistically significant difference, it was observed that students with ID and autism had higher bent arm hang levels than the students with DS. A significant difference was found between the post-test values of shuttle run levels of the students $($ Chi-Square $=11.533 ; \mathrm{p}<0.05)$. "MannWhitney U Test" was used in order to determine which groups had significant difference. Thus, a significant difference was found between the students with ID and DS and the students with autism in favor of the students with ID and DS. 
It was found that the values of shuttle run levels of the students with ID and DS were more positive than the students with autism. A significant difference was found between the post-test values of flexibility levels of the students (Chi-square = 11.533; p <0.05). "Mann-Whitney U Test" was used in order to determine which groups had significant difference. Thus, a significant difference was found between the students with DS and the students with ID and autism in favor of the students with DS. It was found that the flexibility level values of the students with DS were higher than the students with ID and autism.

\section{The results according to the disability type}

According to the disability level variable, The Mann-Whitney U Test was used to determine whether there was a significant difference between the post-test values of flamingo balance, tapping disc, standing long jump, hand grip, bent arm hang, 10x5 shuttle run and sit-and-reach levels of the students. The findings were indicated in Table 9.

Table 9. Values of flamingo balance, tapping disc, standing long jump, hand grip, bent arm hang, 10x5 shuttle run and sit-and-reach test levels according to the disability level variable of the students.

\begin{tabular}{lcccccccc}
\hline & $\begin{array}{c}\text { Flamingo } \\
\text { Balance } \\
\text { Test }\end{array}$ & $\begin{array}{c}\text { Tapping } \\
\text { Disc }\end{array}$ & $\begin{array}{c}\text { Standing } \\
\text { Long Jump }\end{array}$ & $\begin{array}{c}\text { Hand } \\
\text { Gripping }\end{array}$ & Sit-Up & $\begin{array}{c}\text { Bent Arm } \\
\text { Hang }\end{array}$ & $\begin{array}{c}\text { 10x5 } \\
\text { Shuttle } \\
\text { Run }\end{array}$ & $\begin{array}{c}\text { Sit-and- } \\
\text { Reach }\end{array}$ \\
\hline Moderate $(\mathbf{n}=27)$ & $\begin{array}{c}\mathrm{Z}=-1.446 \\
\mathrm{p}=.148\end{array}$ & $\begin{array}{c}\mathrm{Z}=-2.593 \\
\mathrm{p}=.010\end{array}$ & $\begin{array}{c}\mathrm{Z}=-1.210 \\
\mathrm{p}=.226\end{array}$ & $\begin{array}{c}\mathrm{Z}=-0.856 \\
\mathrm{p}=.392\end{array}$ & $\begin{array}{c}\mathrm{Z}=-3.184 \\
\mathrm{p}=.001\end{array}$ & $\begin{array}{c}\mathrm{Z}=-1.333 \\
\mathrm{p}=.183\end{array}$ & $\begin{array}{c}\mathrm{Z}=-4.128 \\
\mathrm{p}=.000\end{array}$ & $\begin{array}{c}\mathrm{Z}=-1.956 \\
\mathrm{p}=.051\end{array}$ \\
Severe $(\mathbf{n = 1 4})$ & $\mathrm{p}$ & & & & & & &
\end{tabular}

n: Number of subjects, Z: Difference score, $\mathrm{p}$ : Statistical significance was determined as $\mathrm{p}<0.05$.

When the data in Table 9. were examined respectively, no significant difference was found between the post-test values of balance levels of the students according to the disability level variable $(Z=-1.446 ; p>0.05)$. A significant difference was found between the post-test values of fastness levels of the students reciprocally $(\mathrm{Z}=$ $-2.593 ; \mathrm{p}<0.05)$. No significant difference was found between the post-test values of standing long jump levels of the students reciprocally $(\mathrm{Z}=$ $1.210 ; p>0.05)$. No significant difference was found between the post-test values of hand grip levels of the students reciprocally $(Z=-0.856$; $\mathrm{p}$ > $0.05)$. A significant difference was found between the post-test values of sit-ups levels of the students reciprocally ( $Z=-3.184 ; p<0.05)$. No significant difference was found between the post-test values of bent arm hang of the students reciprocally $(\mathrm{Z}=$ 1.333; $p>0.05)$. A significant difference was found between the post-test values of shuttle run levels of the students reciprocally $(Z=-4.128 ; p$ $<0.05)$. No significant difference was found between the post-test values of flexibility levels of the students reciprocally $(Z=-1.956 ; p>0.05)$.

\section{DISCUSSION}

The aim of this study was to compare the acqusition sufficiency of goals of physical education lessons to which male and female students with moderate and severe ID, DS and Autism between 11-17 years of age attended with Eurofit test battery. The results obtained from our applications were compared. Our study was successfully applied to a total of 41 students consisting of 32 male and 9 female students attending to the physical education classes in Recep Birsin Özen Special Education Center in Erzurum. In the anthropometric tests applied to the students participating in our research, 51.2\% of the students were between $140-160 \mathrm{~cm}$ in length and $48.8 \%$ of them were between 161-181 $\mathrm{cm}$. The weight of $48.8 \%$ of the students was between $39-55 \mathrm{~kg}$ and $51.2 \%$ of them were more than $55 \mathrm{~kg} .78 \%$ of the students were males and $22 \%$ were females. $70.7 \%$ of the students had ID, $14.6 \%$ with DS and $14.6 \%$ had autism. The disability level of $65.9 \%$ of the students was moderate and $34.1 \%$ was heavy. Significant differences were found between pre-test and posttest values of flamingo balance, tapping discs, standing long jump, shuttle run and sit-and-reach levels. Although there was an increase in bent arm hang, sit-ups and hand grip results, no statistically significant difference was found. According to these results, it was thought that the goals chosen depending on the physical education program mostly had a positive effect on the motor development of children with ID, DS and 
Autism. Flamingo balance test, arm movement speed, grip strength, trunk strength and flare length values of the children were found significant. In this study according to the gender variables a significant difference was found the post-test values of standing long jump, hand grip, bent arm hang levels of the students. No significant difference was found between the post-test values of balance, plate tapping, sit-ups, shuttle run and sit and reach levels the students. When it was compared with the study by Kaya et al.(2018), hand grip strength levels was similar and plate tapping and sit-ups, flamingo balance post-test levels weren't parallel with our study. Since post-tests levels of standing long jump and flexibility in the study have no difference, the results weren't support our study.

In our study according to the weight variable no significant difference was found between the post-test values of balance, fastness, standing long jump, sit-ups, shuttle run and sit and reach levels of the students and a significant difference was found between the post-test values of hand grip strength levels of students. In the study by Salaun and Berthouze-Aranda (2012) significant differences between non-obese and obese boys were found for standing long jump test, sit-andreach test, sit-up test and the shuttle run test; and between normal and obese girls for plate tapping, sit-ups and the shuttle run test. For both boys and girls, the differences between obesity groups were not significant for sit and reach levels. These results weren't parallel with our study. Overweight boys demonstrated better performance than obese boys in sit-up, in sit-and-reach test and for the standing broad jump test. According to these results, the study supported our study.

In the study on children with DS by El et al. (2020), a negative relationship was found between fat weight and sit and reach performance. The children who had high-fat weight were found to be less successful in the sit and reach than children with low-fat weight. In our study, although there was no significant difference between sit and reach levels according to the weight variable, the results was similar to the study. In another study by Demirel and Şirinkan (2018), according to pretest and posttest results of the study; significant diferences were found between pre-test and posttest results of flamingo balance test, sit and reach flexibility test, standing long jump test, right handgrip test, sit-ups in 30 seconds test, bent arm hang in 30 seconds test, vertical jump test of eurofit tests. However, no significant data were found between pre-test and post-test results of tapping discs test, 10x5 meter shuttle run and lefthand grip test. According to the these results, this study data supported our study.

According to the results of a study by Demirel et al. (2016); generally, while observing improvment in the tests regarding the major muscle groups(leg), in the tests regarding the minör muscle groups(hand), no meaningful development results were achieved. In the results of our study, no statistically significant difference was found regarding hand gripping test. So the results was similar. At the results of the study by Sirinkan (2011), the levels of flamingo balance test, plate tapping test, sit and reach, standing long jump, handgrip test, sit-ups test,bant arm hang, 10x5 meters suttle run test were significant improved. Although there wasn't a significiant diffirance only in bent arm hang, sit-ups and hand grip test results, according to the other results of the study our study was parallel. It was reported that sport is vital for handicapped rehabilitation in gaining balance, muscle control, freedom in movements, and coordination (Yüksel, 2018). The data obtained were in parallel with the study data of Biçer et al. (2004). As a result of a 3-month exercise program applied for the individuals with ID, the development of jump, leap, hand grip, push-ups, reverse and straight sit-ups, sit-and-stand movements levels supports our study.

In a study planned by Yanardag et al. (2009) to determine the effects of different adapted exercise programs on the physical fitness levels of individuals with autism, they found that adaptive exercise programs implemented in water and on land for autistic children improved physical fitness and thus they supported our results. In another study, Kubilay et al. (2011) performed balance and posture exercises with exercise ball three times a week and during 8 weeks. They observed an improvement in balance levels of students. Thus, they support the conclusion that improving the balance levels of the students in our study. In addition, Kubilay et al. found that this balance program produced an increase in the level of sit-ups movement. This result showed that the goals we applied for balance contributed to the development of force. No significant difference was found between post-test values regarding shuttle run, balance and 
sit-ups movement levels in the comparisons made However, it was concluded that the students who were taller had higher values for shuttle run,

In terms of height variable, although there was no significant difference between the pre-test and post-test values of the data obtained from tapping discs test, it was seen that taller students had relatively better results. As a result of the tests, it was determined that the post-test values of standing long jump, hand grip and bent arm hang levels were significantly higher in the taller students. No significant difference was found in the results of flexibility levels of the students according to height variable. However, the shorter students had higher flexibility levels than the taller students.

No significant difference was found between the post-test values of flamingo balance, tapping discs, standing long jump, sit-ups, bent arm hang, shuttle run and sit-and-reach levels of the students with ID according to the weight variable. However, although no statistically significant difference was found between the post-test values of flamingo balance, tapping discs, standing long jump, sit-ups and shuttle run levels, it was observed that these parameter values were relatively higher for the students with low weight than the students with high weight. In addition, although no statistically significant difference was found between the post-test values of the bent arm hang and the flexibility levels of the students with ID, it was observed that these parametric values were relatively higher for the students with high weight than the students with low weight. A significant difference was found between the post-test values of the hand grip levels of the students according to the weight variable. As a result, it was concluded that the hand grip levels of the overweight students with ID were higher.

When the gender variable of the students with ID in the research group was examined, no equal distribution was observed. Although no significant difference was found between the post-test values of flamingo balance, tapping discs, sit-ups, shuttle run and flexibility levels of the students, the values regarding flamingo balance, touching discs, shuttle movement and shuttle running levels were higher in favor of male students; the values regarding flexibility levels were higher in favor of female students. When the gender variable was examined, a according to the height of the students. balance and sit-ups movement values than the relatively the shorter students.

significant difference was found between the post-test values of standing long jump, hand grip and bent arm hang levels of the students with ID. It was concluded that this difference was positive for male students.

When the results were examined according to the disability types of the students, the variables were ID, autism and DS. No significant difference was found between the post-test values of flamingo balance, tapping discs, standing long jump, bent arm hang levels of the students. However, it was concluded that the values related to the level of balance differed positively in favor of the students with ID and DS. According to the post-test results of tapping discs test, it was concluded that the levels of the students with ID and autism were higher than the students with DS. Although no significant difference was found between standing long jump values, post-test scores were found higher in favor of the students with ID and autism. In addition, although no significant difference was found between the post-test values of bent arm hang, it was concluded that the results were higher in favor of the students with ID and autism.

Significant differences were found between the post-test values of hand grip, sit-ups, shuttle run and sit-and-reach levels according to the type of disability. The post-test values of hand grip levels were found higher in favor of the students with ID and autism. The post-test values of situps level made a positive difference for the students with ID and DS. A positive difference was found between the post-test values of shuttle run levels in favor of the students with ID and DS. A significant difference was found between the post-test values of sit-and-reach levels in favor of the students with DS.

In another study, Connoly et al. (1986) who performed the Bruininks Oseretsky motor competence test found that the running speed, balance, strength and visual motor control levels of the individuals without DS were positively different from the levels of the individuals with DS relatively. In this study conducted by Connoly et al. (1986), it was found that the values of gross motor and fine motor skill levels of children without DS were significantly higher than the values of children with DS. 
In this study comparison regarding gender variable, Connoly et al. (1986) found no significant difference between the test results of males and females with DS and in the same way, they found no significant difference between the test results of males and females without DS. Consequently, Connoly et al. (1986) argued that there were significant differences between gross and fine motor skills of the children with and without DS and this study supports the results of our study.

In another study, Arslan et al. (2015) observed the gross motor development as a result of a 12-week program on 14 boys with atypical autism and a mean age of 10 years. As a result, they found a significant increase between the pretest and post-test values of running speed, balance and long jump levels. This result is in parallel with the similar parameters of our study. When the results of the disabillity level variable were examined, although no significant difference was found between the post-test values of flamingo balance, standing long jump, hand grip, bent arm hang and sit-and-reach levels of the students with moderate and severe ID, it was concluded that the students with moderate ID had higher values of this parameter than the students with severe ID and this was an expected result. A significant difference was found between the post-test values of tapping discs, sit-ups and shuttle run levels of the students and this difference was in favor of the students with moderate disabilities. It was thought to be an expected result of the test applied to the sample of our study.

In a study to investigate the effects of exercise on the physical fitness levels of the individuals with ID with Eurofit tests, Golubovic et al. (2012) stated that the type of exercise made a difference rather than the type of disability in the test results. In this study, it was found that the children with borderline ID improved better performance at balance, cardiorespiratory endurance, and bent arm hang and the children with mild ID improved better performance at standing long jump and abdominal muscle endurance. In this study, Golubovic et al. (2012) found the children with mild ID had better values in the long jump test, which requires speed, good coordination and explosive movement, which was not characteristic for these individuals but they stated that this would not be generalized. However, they said that these abilities were highly improvable for children with ID. As a result, it was determined that the results obtained from the tests we conducted at the end of our physical education program goals were parallel to these results.

In a study conducted by Giagazoglou et al. (2013) to investigate the effects of trampolin exercise on balance and motor performance of children with ID, significant performance improvements were observed according to the post-test results of a 12-week study with different trampolin exercises. They explained that this balance development occurred as a result of the adaptation of the motor sensors of the participants to the unstable trampoline surface and the effort to maintain the balance. Giagazoglou et al. (2013) stated that as a result of their study, a wellplanned exercise program would contribute to the development of skill that could make motor performance and balance successful.

The general motor performance of persons with various levels of mental disability and various age and gender plays an important role in their social life. A lower performance level impairs the co-existence with their environment and cooperation with others, thus their social health. A higher level is a chance for a longer independent life. It makes sense for these people to take care of their performance. At present, attention is focused not only on the life span, but also on its quality(Bartík \& Bolach, 2015)

\section{Conclusion}

According to these results, in the physical education and sports classes, it was seen that the goals chosen according to the students' level improved the physical capacities of the students in general. According to these results, it was seen that the individual goals chosen for the students in special education schools affiliated to the Republic of Turkey Ministry of National Education contributed to the development of balance, fastness, leg strength, upper body movement speed and flexibility of the students and did not only contribute to the development of hand strength, arm strength and abdominal muscle of the students. The results of our study and the results of previous studies are parallel. Hand and arm strengths of individuals with special needs are important in order to perform their daily life skills (dressing, eating and drinking, self-care) efficiently. 
Therefore, in order to use the hands or arms in a coordinated manner and to perform daily tasks comfortably, the selection of appropriate goals is important for the children with special needs to make their self-care skills and daily life skills comfortable and independent. To achieve the target in the shortest time and in the most efficient way, support materials (appropriate size for the student hand strength tools, rubber ball, plates band, medicine ball) can be used. Students with special needs who have physical disabilities or who have priority in physical development can be included in special studies except physical education and sports lessons and academic studies. Physical education and sports class hours can be increased to contribute to the development of individuals with special needs.

Conflicts of Interest: The authors declare no conflict of interest.

Knowledge: This article is extracted from my master thesis entitled "The Investigation of Acquisition Sufficiency of Physical Education Lesson Aims in Recep Birsin Özen Special Education School in Erzurum City Center", (Master Thesis, Atatürk University, Erzurum/Turkey, 2017).

\section{REFERENCES}

Adam, C., Council of, E., Committee for the Development of, S., Council of, E., \& Committee of Experts on Sports, R. (1988). Eurofit : handbook for the Eurofit tests of physical fitness. Rome: Italian National Olympic Committee, Central Direction for Sport's Technical Activities Documentation and Information Division.

Arslan, E., \& Ince, G. (2015). The effects of 12 weeks exercise program on the level of gross motor skill of the children with atypical autism. International Journal of Sports, Exercise and Training Science, 1(1), 51-62.

Bartík, P., \& Bolach, B. (2015). Evaluation of general motor performance in older school age pupils with a moderate mental disability. The New Educational Review, 42(4), 253-263. doi:10.15804/tner.2015.42.4.21

Baştürk, R. (2011). Nonparametric Statistical Methods with Spss Sample in All Aspects (Vol.

2). Ankara: Anı Publishing.

Beasley, C. R. (1982). Effects of a jogging program on cardiovascular fitness and work performance of mentally retarded adults. American Journal of Mental Deficiency, 86(6), 609-613.

Biçer, Y., Savucu, Y., Kutlu, M., Kaldırımcı, M., \& Pala, R. (2004). The effect of power and strength exercises on movement competence and ability of mentally disabled children. Research of Eastern Anatolia Region, 3(1), 173-179.

Büyüköztürk, Ş. (2010). Manual of data analysis for social sciences (Vol. 11). Ankara: Pegem Academy Publishing.

Connolly, B. H., \& Michael, B. T. (1986). Performance of retarded children, with and without Down syndrome, on the Bruininks Oseretsky Test of Motor Proficiency. Physical Therapy, 66(3), 344-348.

Demirel, N., Sirinkan, A., \& Sirinkan, Ş. Ö. (2016). Pre-school students investigation of physical improvement with Eurofit tests studying gymnastics at the summer school (Erzurum sample). International Journal of Social Sciences and Education Research, 2(2), 688694. Retrieved from http://dergipark.gov.tr/ijsser

Demirel, N., \& Şirinkan, A. (2018). The Effect Of Special Activity Education Program Applied In Special Education Rehabilitation Centers To Female Students. European Journal of Special Education Research, 3(1), 42-51. doi:10.5281/zenodo. 1135330

El, Ç., Hüzmeli, E. D., \& Gökçek, Ö. (2020). Investigation of the Relationship between Physical Activity and Body Mass Index in Children with Down Syndrome. J Pediatr Res, $7(2)$, 92-96. doi:10.4274/jpr.galenos.2019.95530

Ersoy, G. (2004). Nutrition for Exercise and Sport People (Vol. 3). Ankara: Nobel Publishing.

Giagazoglou, P., Kokaridas, D., Sidiropoulou, M., Patsiaouras, A., Karra, C., \& Neofotistou, K. (2013). Effects of a trampoline exercise intervention on motor performance and balance ability of children with intellectual disabilities. Res Dev Disabil, 34(9), 27012707. doi:10.1016/j.ridd.2013.05.034

Golubović, Š., Maksimović, J., Golubović, B., \& Glumbić, N. (2012). Effects of exercise on physical fitness in children with intellectual disability. Research in Developmental Disabilities, 33(2), 608-614. doi:https://doi.org/10.1016/j.ridd.2011.11.003

Gündüz, N. (1997). Training Informations(Vol. 2). İzmir: Saray Publishing. 
İlhan, E. L., Kırımoğlu, H., Tunçel, M., \& Altun, M. (2015). The effect of special athletics training to self-care skills' level on mentally retarded children. Journal of Kirsehir Education Faculty, 16(3), 145-160.

Kaya, M., Koca, F., Kaynak, K., \& Özkatar Kaya, E. (2018). Evaluation Of The Eurofit Test Battery On Trainable Mentally Disabled Elementary School Students. Ovidius Universty Annals, Series Physical Education And Sport, Science, Movement And Health, 18(2), 192-196.

Kınalı, G. (2016). Children Developing Differently. In A. Kulaksizoğlu (Ed.), Physical - Art Music Education for the Mentally Handicapped (Vol. 3, pp. 190). İstanbul: Nobel Publishing.

Kolukısa, Ş., Torun, K., \& Özdağ, S. (1995). Comparison of anthropometric and physical fitness values of 12-15 age group football players with the sedentary group. Journal of Football Science and Technology, 3(1), 17-22

Kubilay, N. S., Yildirim, Y., Kara, B., \& Harutoglu Akdur, H. (2011). Effect of balance training and posture exercises on functional level in mental retardation. Physiotherapy Rehabilitation, 22(2), 55-64.

Salaun, L., \& Berthouze-Aranda, S. E. (2012). Physical fitness and fatness in adolescents with intellectual disabilities. J Appl Res Intellect Disabil, 25(3), 231-239. doi:10.1111/j.14683148.2012.00659.x

Sirinkan, A. (2011). Study of physical suitability of football school students in 7-12 age group with tests of eurofit (the sample of erzurum). $e$ Journal of New World Sciences Academy, 6(3), 178-184.

Sirinkan, A. (2018). The Impact Of Therapeutic Recreational Exercises On Development In Basic Skills Of Male And Female Students With Down Syndrome. European Journal of Special Education Research, 3(4), 267-277. doi:10.5281/zenodo.1491854

Sirinkan, A., \& Saraçoğlu, R. N. (2017). The Investigation Of The Effects To Physical Parameters Of 24 Weeks Special Movement Training Program Which Is Applied To Autistic Children With Eurofit Tests.
European Journal of Physical Education and Sport Science, 3(7), 141-153. doi:10.5281/zenodo.841325

Tsigilis, N., Douda, H., \& Tokmakidis, S. P. (2002). Test-retest reliability of the Eurofit test battery administered to university students. Perceptual and Motor Skills, 95, 1295-1300.

Van Der Niet, A. G., Hartman, E., Moolenaar, B. J., Smith, J., \& Visscher, C. (2014). Relationship between physical activity and physical fitness in school-aged children with developmental language disorders. Res Dev Disabil, 35(12), 3285-3291. doi:10.1016/j.ridd.2014.08.0224

Virgil, T., Mujea Ana-Maria, \& Cristina-Georgiana, V. (2015). Study regarding speed development of visually impaired pupils from 7th and 8th grades using differentiated instruction. Science, Movement and Health, 15(2), 177182.

Yalçın, Y. G., \& Akkuş, H. (2006). Child and Basketball (Vol. 1). Ankara: Nobel Publishing.

Yanardağ, M., Ergun, N., \& Yılmaz, İ. (2009). Effects of adapted exercise education on physical fitness in children with autism. Physiotherapy Rehabilitation, 20(1), 25-31.

Yörükoğlu, A. (2000). Family and Child in a Changing Society. İstanbul: Aydın Publishing.

Yüksel, M. F. (2018). Examination of the physical profiles of physically handicapped female badminton players. Turkish Journal of Sport and Exercise, 1-8. doi:10.15314/tsed.364194

Zorba, E., Ziyagil, M., Çolak, H., Kalkavan, A., Kolukısa, Ş., Torun, K., \& Özdağ, S. (1995). 12-15 yaş grubu futbolcuların antropometrik ve fiziksel uygunluk değerlerinin sedanter grupla karşılaştırılması. Futbol Bilim ve Teknoloji Dergisi, 3(1), 17-22.

How to cite this article: Nişli M.Y., Şirinkan, A., Acar, Z.A., Öz Nişli, E. and Toy, H. (2021). The Investigation of Acquisition Sufficiency of Physical Education Lesson Aims in A Special Education School in Turkey: A Pilot Study. Int J Disabil Sports Health Sci;4(1):24-37.

https://doi.org/10.33438/ijdshs.800381

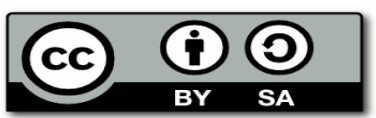

CAuthor(s) 2021 by the authors. This

work is distributed

under https://creativecommons.org/licenses/by-sa/4.0/ 